\title{
Enhancing the performance of cascaded three-level VSC STATCOM by ANN controller with SVPWM integegration
}

\author{
Mohamad Milood Almelian', Izzeldin. I. Mohd ${ }^{2}$, Abu Zaharin Ahmad ${ }^{3}$, Mohamed Salem ${ }^{4}$, \\ Mohamed A. Omran ${ }^{5}$, Awang Jusoh ${ }^{6}$, Tole Sutikno ${ }^{7}$ \\ ${ }^{1,2,3,5}$ Faculty of Electrical and Electronics Engineering, Universiti Malaysia Pahang, Malaysia \\ ${ }^{4}$ School of Electrical and Electronic Engineering, Universiti Sains Malaysia, Malaysia \\ ${ }^{6}$ Faculty of Electrical Engineering, Universiti Teknologi Malaysia, Malaysia \\ ${ }^{7}$ Department of Electrical Engineering, Universitas Ahmad Dahlan, Indonesia
}

\begin{tabular}{l} 
Article Info \\
\hline Article history: \\
Receive Jan 21, 2019 \\
Revised Apr 17, 2019 \\
Accepted May 11, 2019 \\
\hline Keywords: \\
ANN controller \\
Cascaded H-bridge three-level \\
VSC STATCOM \\
PI controller \\
Power factor \\
SVPWM technique
\end{tabular}

\begin{abstract}
This article presents a cascaded three-level voltage source converter (VSC) based STATCOM employing an artificial neuron network (ANN) controller with a new simple circuit of space vector pulse width modulation (SVPWM) technique. The main aim of utilizing ANN controller and SVPWM technique is to minimize response time (RT) of STATCOM and improve its performance regard to PF amplitude, and total harmonic distortion (THD) of VSC output current during the period of lagging/leading PF loads (inductive/capacitive loads). The performance of STATCOM is tested using MATLAB/SIMULINK in IEEE 3-bus system. The simulation results clearly proved that the STATCOM with intelligent controller is more efficient compared to a conventional controller (PI controller), where ANN enables the voltage and current to be in the same phase rapidly (during 1.5 cycles) with THD less than $5 \%$.
\end{abstract}

Copyright $(2019$ Institute of Advanced Engineering and Science. All rights reserved.

\section{Corresponding Author:}

Mohamad Milood Almelian,

Faculty of Electrical and Electronics Engineering,

Universiti Malaysia Pahang (UMP),

26600 Pekan, Pahang, Malaysia.

Email: Almalyan84@gmail.com

\section{INTRODUCTION}

The widespread use of power electronic-based equipment and inductive/capacitive loads have brought power quality problems in distribution systems. The most common power quality problems today are low PF and harmonic distortion [1, 2]. The low PF and Harmonic currents in the distribution system can cause heating in the electrical equipment, vibration/noise in machines, and malfunction of the sensitive equipment [3]. Conventional compensators such as a fixed capacitor and reactor banks and static VAR compensators have been widely used for the improvement of electric power quality. With the advancement of microprocessor and semiconductor technology, cascaded multilevel VSC-based custom power devices have been introduced in distribution systems. STATCOM is a VSC-based custom power device and meets the load current compensation requirements such as reactive power compensation [4-6].

The performance of STATCOM is mainly depending on the accurately and speed error signals are compensated. Therefore, a control algorithm is the most important part of a STATCOM used for dynamic control of reactive power [7, 8]. In general, the PI controller is widely used as a control unit of STATCOM device due to its simple and easy to implement. There is a number of studies introduced by researchers that related to the STATCOM based on PI controller in order to detect the PF of the power system. The basic operating principle of STATCOM with direct current control scheme depended on PI controller for PF improvement under linear and non-linear load condition [9]. The literature in [10] deals with 5-level cascaded 
VSC with SPWM technique and PI controller which established for STATCOM for correcting PF and decreases THD of the system. While, a new approach of the predictive control system based PI controller is used to control the STATCOM for compensating harmonics and enhance PF [11]. PI controller design procedure was given for two-level VSC STATCOM for PF correction in [12]. However, The conventional controller like PI controller requires precise linear mathematical models, which are difficult to obtain and fails to perform satisfactorily under parameter variations nonlinearity load disturbance, etc [13, 14]. Recently, a major effort has been underway to develop new and unconventional control techniques that can often augment or replace conventional control techniques. Unlike their conventional counterparts, these unconventional controllers such as ANN controller can learn, remember and make decisions. Furthermore, it provides fast dynamic response while maintaining the stability of the converter system over a wide operating range.

Currently, various researchers have introduced in literature the improvement of STATCOM performance using ANN techniques [6, 8, 13-15]. These studies are depending on sinusoidal-PWM (SPWM) technique for controlling switching gates of VSC, where SPWM is considered a conventional technology, which has been extensively used because it improves the voltage harmonic components to higher frequencies. However, SVPWM technique has been increasingly used in the last decade because it allows reducing commutation loss and the harmonic current of the output voltage and obtains higher amplitude modulation indexes if compared with the conventional SPWM technique [16]. Moreover, although some these studies were associated to the PF correction, there is no simulation described RT and performance of STATCOM with regard to PF amplitude and THD during a period of lagging/leading PF load.

In this paper, Cascaded 3-level VSC STATCOM is controlled by ANN with a new simple circuit of SVPWM technique. The new circuit is much simpler and more executable than conventional SVPWM without look-up tables or complex logical judgments. This combination (STATCOM) offers speedy PF correction with very low THD for VSC output current.

\section{CONFIGURATION OF PROPOSED STATCOM}

In this research, the modeling of STATCOM is presented in the three-phase IEEE 3-bus test system. The test system is including two AC power supply (G1, G2), two types of loads (inductive and capacitive), and STATCOM device circuit as described in Figure 1.

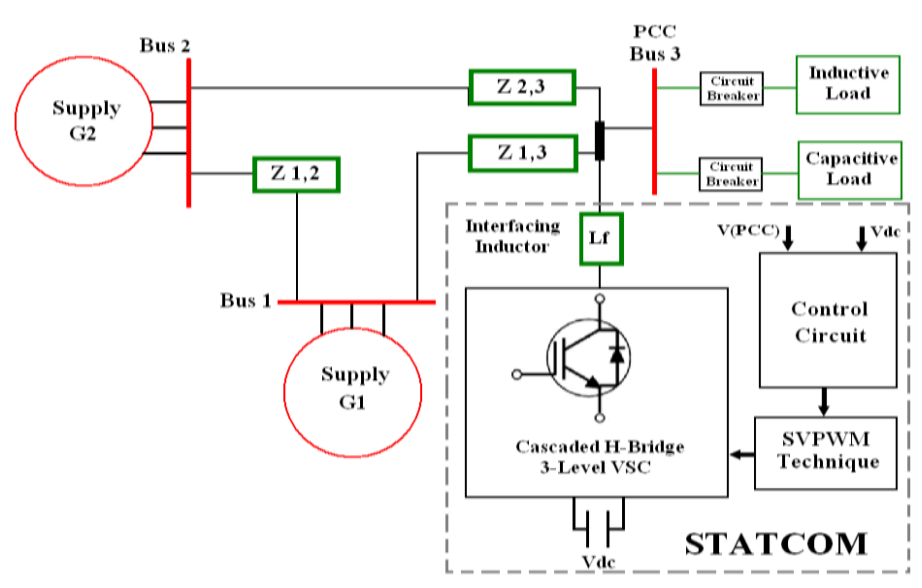

Figure 1. Proposed of STATCOM circuit connected to IEEE 3-Bus system

STATCOM is a converter-based custom power device. It consists of a cascaded 3-level VSC, coupling inductance (Lf) which represented L filter, SVPWM technique, and control circuit, where the VSC is a basic building block of STATCOM.

\subsection{Cascaded H-bridge three-level VSC}

The multilevel VSC with advantages such as direct connection to the distribution system and improvement of the harmonic content of output voltage compared with conventional two-level VSC operating in the same switching frequency has been used in STATCOM applications. Cascaded multilevel VSC among multilevel VSC topologies is the most popular topology because of using the smallest number of 
components and the flexibility of the circuit layout. Cascaded VSC topology is based on the series connection of H-bridges with separate dc voltage sources. In this VSC structure, the number of output voltage levels can be easily increased by adding or decreased by removing the H-bridges [6, 17]. Nowadays, cascaded H-bridge VSC can be connected to distribution systems without using step-down transformers because of commercially available IGBTs with high voltage and current ratings. Therefore, the VSC can be connected to the power system via Lf. The structure of the H-bridge three-level VSC-based STATCOM is shown in Figure 2. H-bridges are connected to the power system by means of an Lf at the Bus-3 (PCC) and one H-bridge unit is used for each phase.

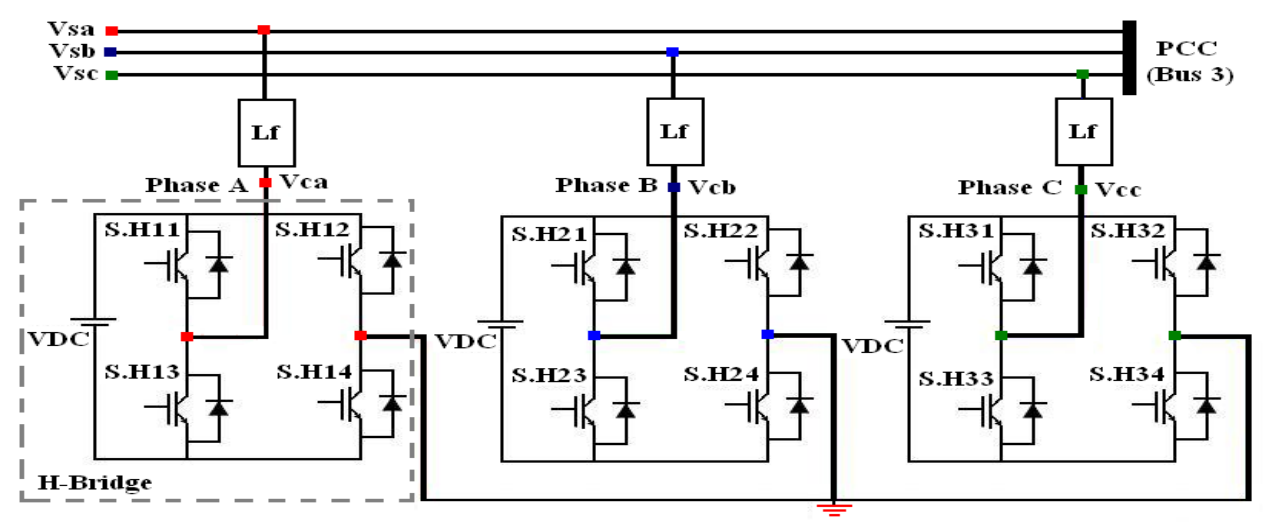

Figure 2. Cascaded H-bridge 3-level VSC

The basic operation principle of the STATCOM is based on two AC sources (System and STATCOM) with the same frequency by means of coupling inductance [18]. Exchange of reactive power between the system and STATCOM is achieved by adjusting the amplitude of the VSC output voltage (Vc). If the amplitude of the VSC output voltage is greater than the system voltage (Vs), the STATCOM generates capacitive reactive power. Otherwise, the STATCOM absorbs inductive reactive power. If the amplitude of the VSC output voltage is equal to the system voltage, the exchange of reactive power between the STATCOM and the system will be zero. Reactive power generated/absorbed by the STATCOM is given by the following equation:

$$
Q=\frac{V_{s}}{X_{L f}}\left(V_{s}-V_{c} * \cos (\alpha)\right)
$$

Where, Q: Reactive power generated or absorbed by the STATCOM, $\mathrm{X}_{\mathrm{Lf}}$ is the reactance of coupling inductance, and the phase angle between the voltage of the VSC output and the system. In STATCOM operation, dc voltages are held by dc-link capacitors. Since there is no energy source connected to the dc-link, net active power transacted by the STATCOM must be zero. In practice, energy losses occur in capacitors and VSC switches. If these losses are not supplied from the system, the capacitors will discharge. To prevent discharging of capacitors, some active power must be drawn from the system. Active power $(\mathrm{P})$ absorbed by the STATCOM is determined as follows:

$$
P=\frac{V_{s} * V_{c}}{X_{L f}} \sin \alpha
$$

The (3) presents the calculation of coupling inductance (Lf) that represented the L filter which used to mitigate harmonics of VSC output.

$$
L_{f}=\frac{1}{8} \times \frac{V_{d c}}{f_{s w} \times \Delta I_{L \max }}
$$

Where $f_{s w}$ is the switching frequency, and $\Delta I_{L \max }$ is the maximum rated load current $I_{L \max }$ peak ripple which equals (5-20\%) of rated supply current of power system. 


\subsection{SVPWM technique signal}

The SVPWM technique has been increasingly used in the last decade to generate the output voltage of VSC because it allows reducing commutation losses and/or the harmonic content of output voltage and to obtain higher amplitude modulation indexes if compared with conventional SPWM technique[19].

In general, the conventional SVPWM implementation involves the following steps: Sector identification in which the instantaneous reference space vector lies, mapping this sector to an appropriate sector in the inner hexagon through coordinate transformations, determination of the inverter vector switching times, and selecting appropriate individual vectors using switching sequence tables [20,21]. Therefore, this section presents a simple and low-cost implementation of SVPWM technique in which the PWM switching times for the inverter legs are directly derived from the sampled amplitudes of the reference phase voltages. The SVPWM technique scheme is displayed in Figure 3, where by comparing output of space vector circuit with PWM signal (carrier signal), the proper pulses for each inverter legs in each phase will be generated [20].

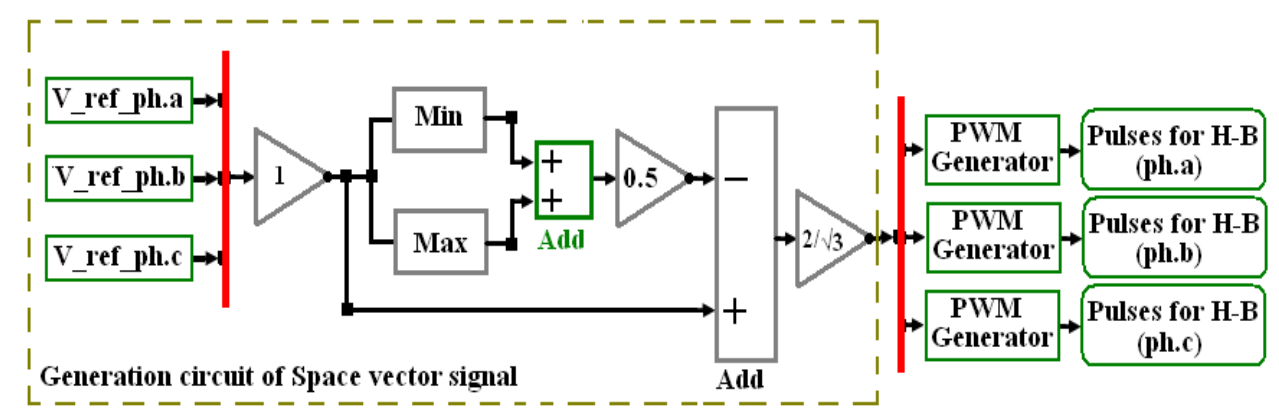

Figure 3. SVPWM scheme

The SVPWM The new SVPWM technique used is completely based upon the instantaneous value of the reference phase voltage of all the phases. To obtain the output signal of the space vector circuit, a reference phase voltages $V_{\text {ref }}$ is added to the common mode voltage $V_{\text {set }}$ which given by equation (4) [19], where the maximum magnitude of the three sampled reference phase voltages is $V_{\max }$ while the minimum magnitude of the three sampled reference phase voltages is $\mathrm{V}_{\text {min }}$.

$$
V_{\text {set }}=-\left(V_{\text {max }}+V_{\text {min }}\right) / 2
$$

The implementation of SVPWM using instantaneous reference phase amplitudes for VSC scheme involves the following steps:

a. Calculate the time equivalent of sampled amplitudes of $\mathrm{V}_{\mathrm{an}}, \mathrm{V}_{\mathrm{bn}}$, and $\mathrm{V}_{\mathrm{cn}}$ for the present sampling interval, where $\mathrm{T}_{\mathrm{S}}$ is the sampling time period.

$$
\begin{aligned}
& T_{a s}=V_{a n} \frac{T_{s}}{V_{d c}} \\
& T_{b s}=V_{b n} \frac{T_{s}}{V_{d c}} \\
& T_{c s}=V_{c n} \frac{T_{s}}{V_{d c}}
\end{aligned}
$$

b. Find $\mathrm{T}_{\text {set }}$ as following

$$
T_{\text {set }}=0.5\left(T_{\max }+T_{\min }\right)
$$

Where $\mathrm{T}_{\max }$ and $\mathrm{T}_{\min }$ are the maximum and minimum of $\mathrm{T}_{\mathrm{as}}, \mathrm{T}_{\mathrm{bs}}$, and $\mathrm{T}_{\mathrm{cs}}$. 
c. Calculate $\mathrm{T}_{\mathrm{a}(\text { gate })}, \mathrm{T}_{\mathrm{b}(\text { gate) }}$, and $\mathrm{T}_{\mathrm{c}(\text { gate) }}$ as:

$$
\begin{aligned}
& T_{a(\text { gate })}=T_{a s}+T_{\text {set }} \\
& T_{b(\text { gate })}=T_{b s}+T_{\text {set }} \\
& T_{c(\text { gate })}=T_{c s}+T_{\text {set }}
\end{aligned}
$$

Where $\mathrm{T}_{\mathrm{a} \text { (gate) }}, \mathrm{T}_{\mathrm{b} \text { (gate) }}$, and $\mathrm{T}_{\mathrm{c}(\text { gate) }}$ are the signals which when compared with high frequency triangular wave in PWM generator, produces the pulses for VSC switches. Figure 4 shows the waveform of signals $\mathrm{T}_{\mathrm{a}(\text { gate) }}, \mathrm{T}_{\mathrm{b} \text { (gate) }}$, and $\mathrm{T}_{\mathrm{c} \text { (gate) }}$ which represented the output of space vector circuit Hence gating signal (pulses) is generated without the requirement of sector angle, also look-up tables for selecting the inverter switching vectors are avoided in this scheme. In this method only sampled reference phase amplitude is required, where the SVPWM circuit can be used for any multilevel VSC configuration and can also work in the over-modulation region.

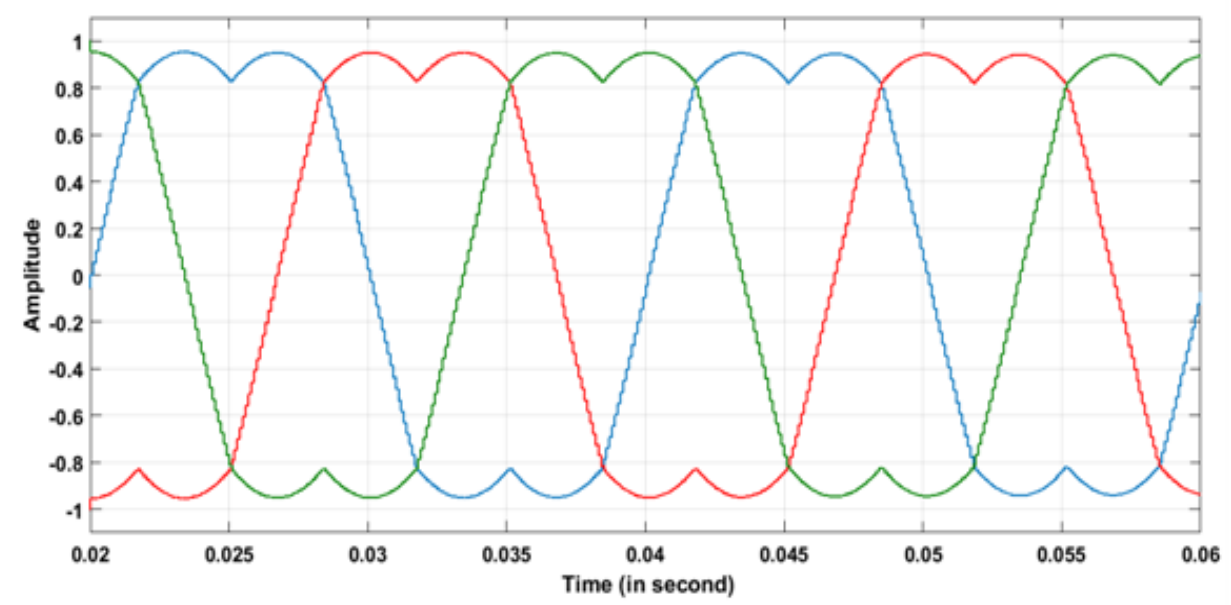

Figure 4. Output signals of space vector circuit

\subsection{Structure of control circuit}

The main objective for STATCOM control circuit is to correct the power factor under lagging/leading PF loads by injecting or absorbing reactive power to or from the power system. The basic control strategy used for the proposed STATCOM controller is direct control. In the case of the direct control scheme, the reactive output current can be controlled directly by the internal voltage control mechanism of the converter (SVPWM) in which the internal dc voltage is kept constant. The STATCOM is controlled to deliver either inductive or capacitive currents to the power system by varying its output voltages Vca, Vcb, and Vec [22]. The direct control scheme employed in this work for cascaded 3-level VSC STATCOM is illustrated in Figure 5.

In the design of the STATCOM controller, the reference PCC voltage (Vbus3_ref) is compared with the actual PCC voltage (Vbus3), and then the difference between these two is processed through a PI/ANN controller (control unit 1) which produces an appropriate value of modulation index (M) needed for maintaining the PF of PCC at the desired value. Besides that, a small amount of active power flow is made possible by phase shifting (lagging) the STATCOM voltage with respect to the PCC voltage by a small angle $(\alpha)$ in order to keep the dc capacitor voltages constant. The $\alpha$ is determined by another PI/ANN controller (control unit 2) according to the difference between Vdc_ref and the Vdc. Finally, to produce the sinusoidal control signals, $\alpha$ and the output of Phase look loop (PLL) ( $\theta$ ) are supplied to the phase shifter block. These control signals are fed to the product block together with MI to create reference signals which passed to the SVPWM block to generate the firing pulses for each H. Bridge [23]. PLL has been used to synchronize the output voltage of the STATCOM with that of the system. 


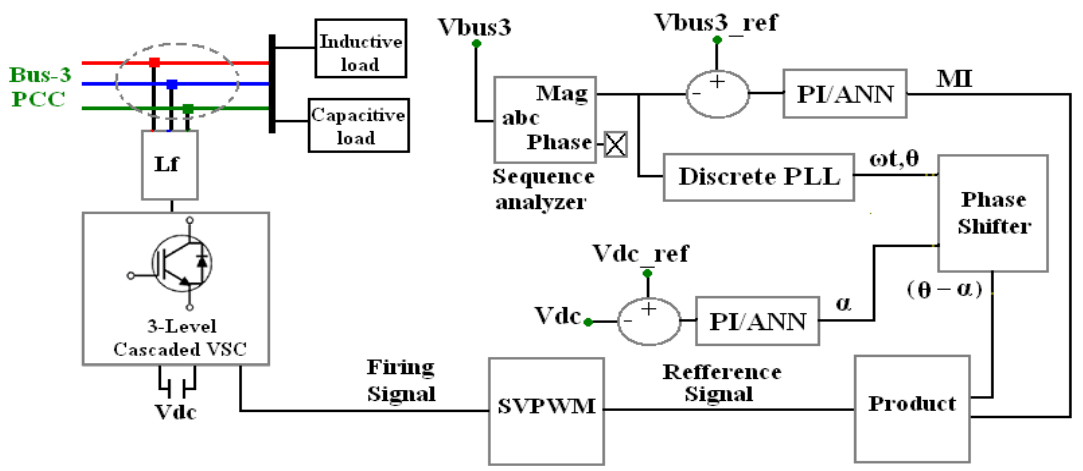

Figure 5. Control circuit of cascaded 3-level VSC STATCOM

\subsubsection{PI controller}

Proportional-integral (PI) Controller is a feedback control unit which generates a gated command to operate the Cascaded 3-level VSC STATCOM and to compensate the error, which has been calculated by comparing desired values against measured values for both reactive /real power control unit (control unite 1 and 2). PI controller outfits a controller with proportional and integral action as depicted in Figure 6.

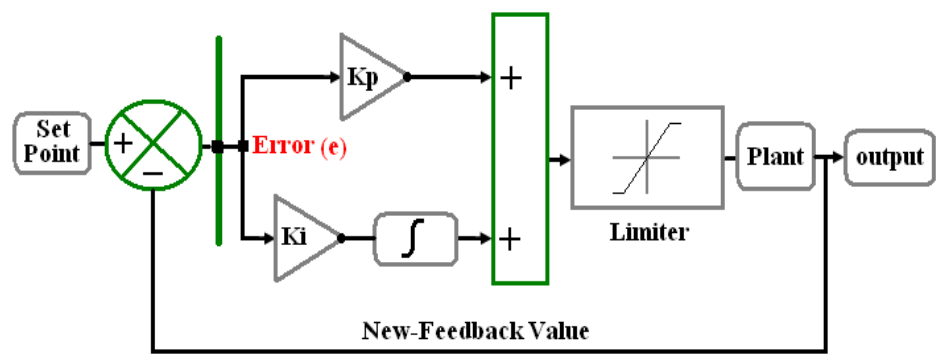

Figure 6. Block diagram of PI controller

The most important object in the PI control diagram is to tune PI parameters ( $\mathrm{Ki}$ and $\mathrm{Kp}$ ), where the correctness of the result totally depends upon these parameters. The value of $\mathrm{Kp}$ and $\mathrm{Ki}$ can find out by using various techniques. In this paper, $\mathrm{KI}$ and $\mathrm{Kp}$ are 25 and 1 respectively for the reactive power control loop, whereas the value of proportional and integral gains for active power control unit is 0.025 .

\subsubsection{ANN controller}

Neural-networks is one of the new technology that is getting fashionable in the present era. ANN is a highly interconnected network of a large number of processing elements called neurons in an architecture inspired by the human brain [7,8]. In general, the structure of the neural network consists of several layers of neurons, an input layer, hidden layers, and output layer as given in Figure 7.

The main aim of the ANN controller is to find suitable values for weights and biases which are the learnable parameters inside the controller structure that cause the desired output. The input to the neural network is the error voltage at the PCC and the error voltage at the dc link. The error is determined and a portion of it is propagated backward through the network [24].

In this paper, the training of a neural network is done offline by the Levenberg-Marquardt backpropagation (LMBP) algorithm that is highly suitable for fast convergence, where the input and output data are stored in the workspace which taken from the conventional PI controller. ANN controller structure has 3 layers composed of one input layer, one hidden layer containes10 neurons, and one output layer, where Figure 8 shows the inner structure of the ANN controller. The number of epoch required to train the ANN controller for the reactive power control unit is 70 and the best validation performance is 0.000301 at epoch 55 while the number of epochs for active power control unit is 60 and the best validation performance is 0.00352 at epoch 45 . 


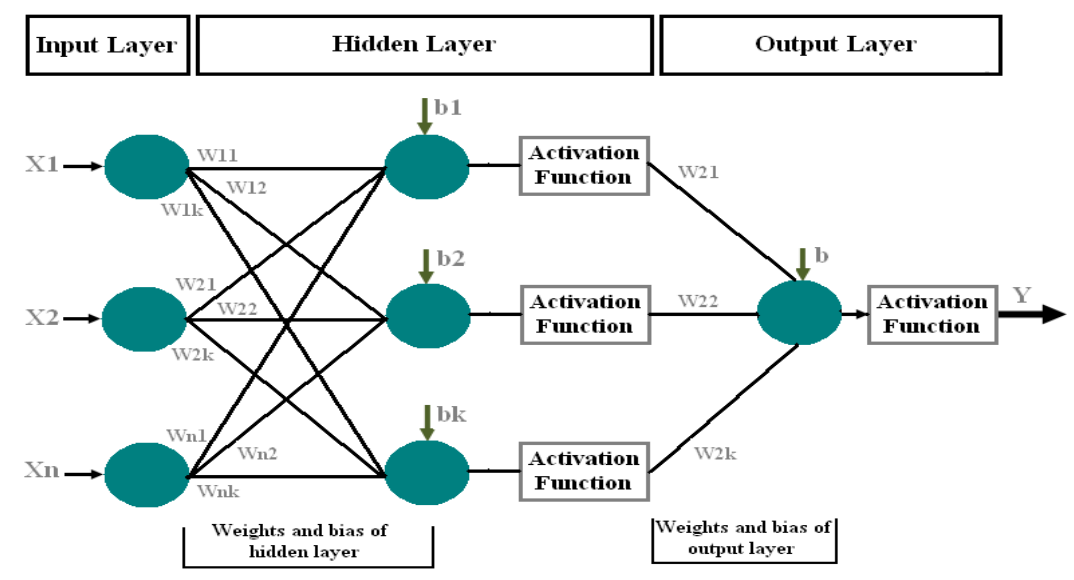

Figure 7. General structure of neural network

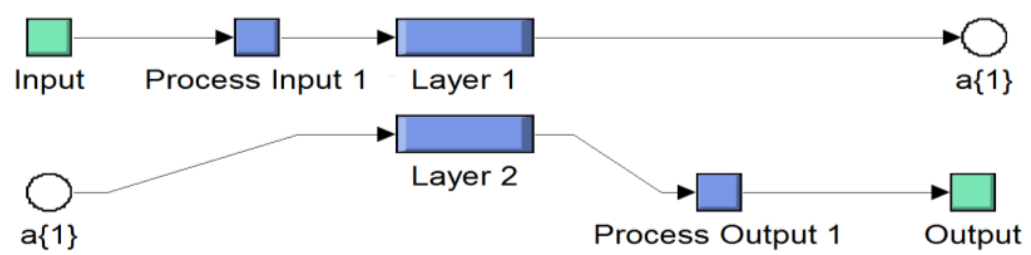

Figure 8. Inner structure of ANN controller

\section{RESULTS AND DISCUSSION}

The circuit of cascaded 3-level VSC STATCOM which connected to bus-3 of the power system (IEEE 3-bus system) as shown in Figure 1 is modeled in MATLAB/Simulink, where the circuit parameters are listed as follows:

- Rated AC voltage is $6.6 \mathrm{kV}_{\mathrm{L}-\mathrm{L}, \mathrm{rms}}$, rated power is $20 \mathrm{MVA}$, resistance is $0.89 \Omega$, impedance is $16.48 \mathrm{mH}$, and, the frequency is $50 \mathrm{HZ}$, the impedance between buses $(\mathrm{Z1}, 2, \mathrm{Z} 1,3$, and $\mathrm{Z} 2,3)$ are $0.05+\mathrm{j} 0.2 \Omega$, $0.02+\mathrm{j} 0.1 \Omega$, and $0.036+\mathrm{j} 0.12 \Omega$ respectively, active power for inductive and capacitive load is $1 \mathrm{MW}$ while inductive/capacitive reactive power is 1MVAR, filter inductance is $10.7 \mathrm{mH}$, DC link voltage is $6 \mathrm{kV}$ and switching frequency is $2 \mathrm{kHz}$.

- The simulation results below illustrate the performance of cascaded 3-level VSC STSTCOM under PI/ANN controller for PF correction and THD of VSC output. The STATCOM performance has evaluated under two cases which are lagging PF load (inductive load) case and leading PF load (inductive load) case, where the transition time for these cases is considered from $0 \mathrm{sec}$ to $1.5 \mathrm{sec}$.

\subsection{Compensation of lagging PF load (Inductive load)}

\subsubsection{PF amplitude during period of inductive load}

The nature of inductive loads is reducing the PF, which tends to 0.71 without utilized STATCOM as demonstrated in Figure 9. Nevertheless, the interference of STATCOM with PI control algorithm bring back the PF to the 0.982 through $0.451 \mathrm{sec}$ because of the STATCOM compensates the lack of reactive power whereas the ideal maximum value of PF (unity) was gained by ANN controller within $0.03 \mathrm{sec}$ as shown in Figure 10 (a) and Figure 10 (b). Here, the ANN controller has reduced the error between the actual value and desired value to the minimum more than the PI controller unit. 


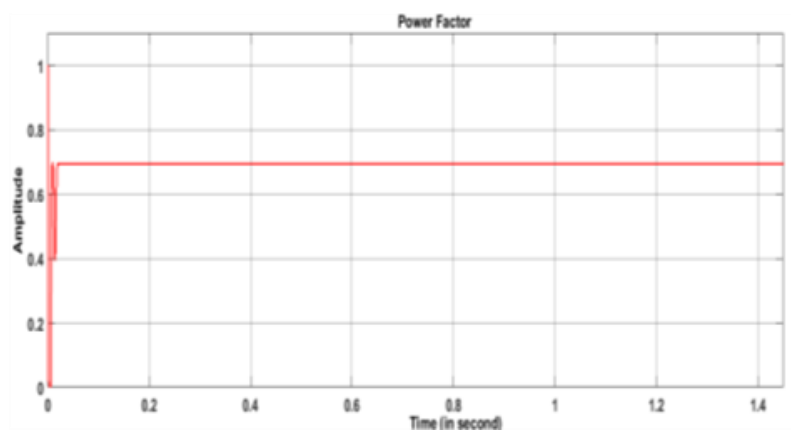

Figure 9. PF of Bus-3 during inductive load period without STATCOM

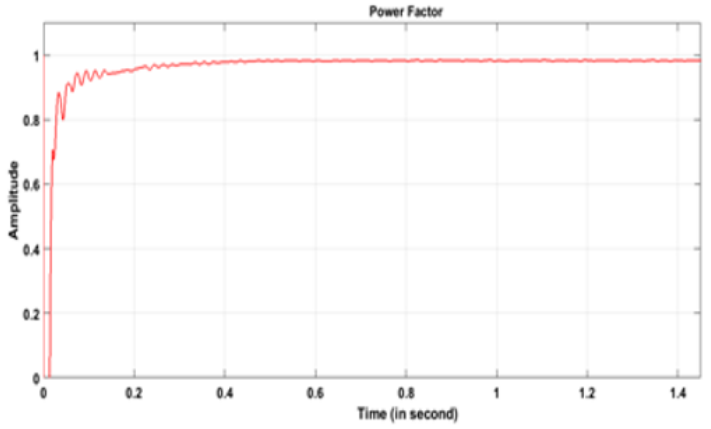

(a)

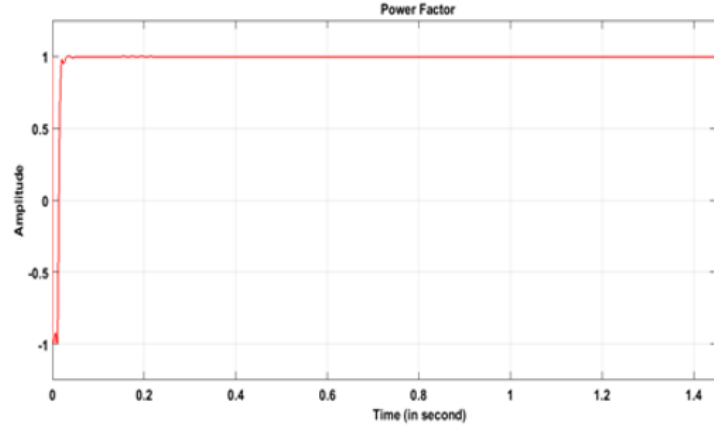

(b)

Figure 10. PF of Bus-3 during inductive load period with STATCOM based on; (a) PI, (b) ANN

\subsubsection{THD value during inductive load period}

ANN controller and SVPWM technique have improved the STATCOM performance for eliminating the VSC output current harmonics, where, the THD of VSC output current was $4.53 \%$ by ANN compared to the results that obtained with PI controller which tend to 5.85\% as presents in Figure 11 (a) and Figure 11 (b).

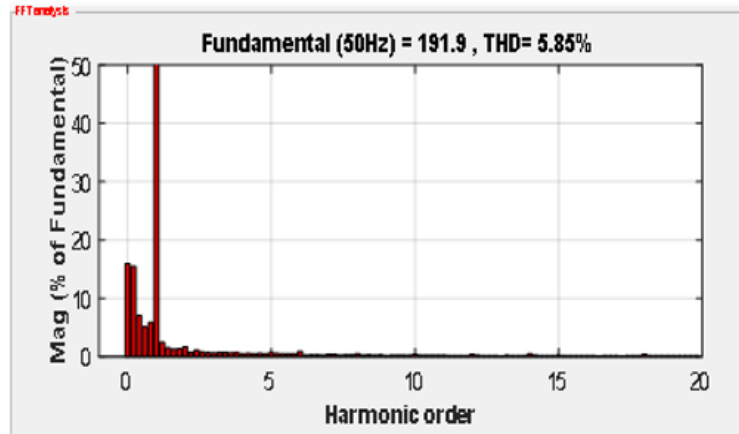

(a)

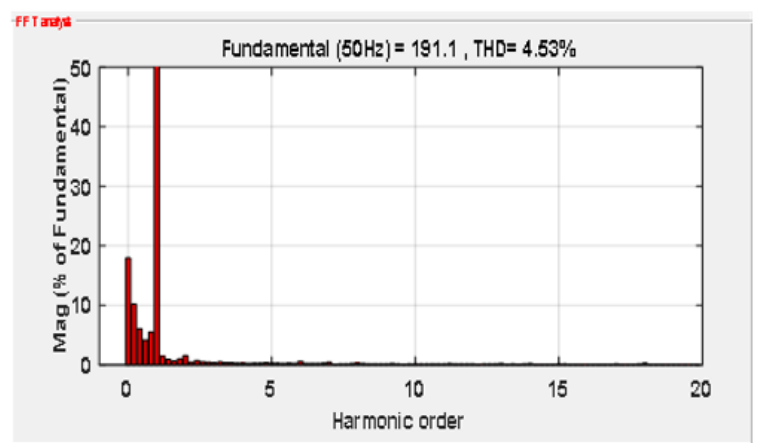

(b)

Figure 11. THD of STATCOM output current during inductive load period. STATCOM based on; (a) PI, (b) ANN

\subsection{Compensation of leading PF load (Capacitive load)}

\subsubsection{PF amplitude during period of capacitive load}

During this case, the current is ahead comparing with the voltage of bus 3 , where the PF measurement recorded 0.69 without STATCOM as displayed in Figure 12. With the absorption of the surplus reactive power by the STATCOM, the PF came back to the 0.983 within $0.788 \mathrm{sec}$ by employing the PI controller. Meanwhile, the performance of ANN aided STATCOM to have unity PF just during $0.035 \mathrm{sec}$ as proved in Figure 13 (a) and Figure 13 (b). The RT of STATCOM is developed by ANN, where in this case, the RT of ANN to PI is $4.44 \%$ that is meaning ANN has improved the time to $95.55 \%$. 


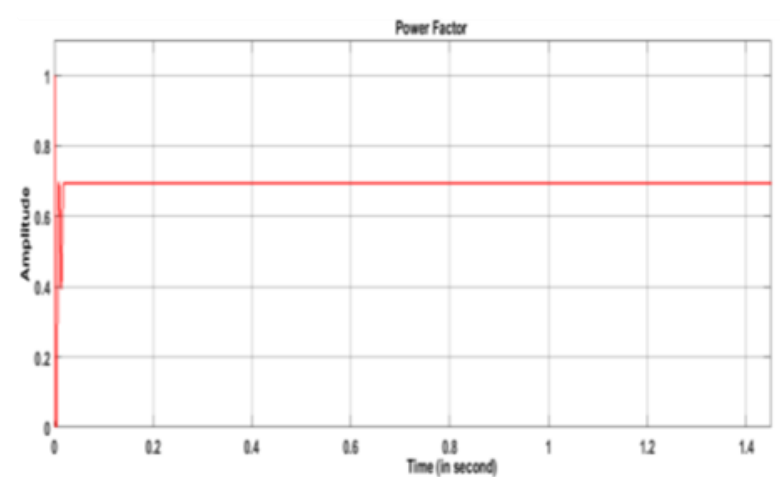

Figure 12. PF of Bus-3 during capacitive load period without STATCOM

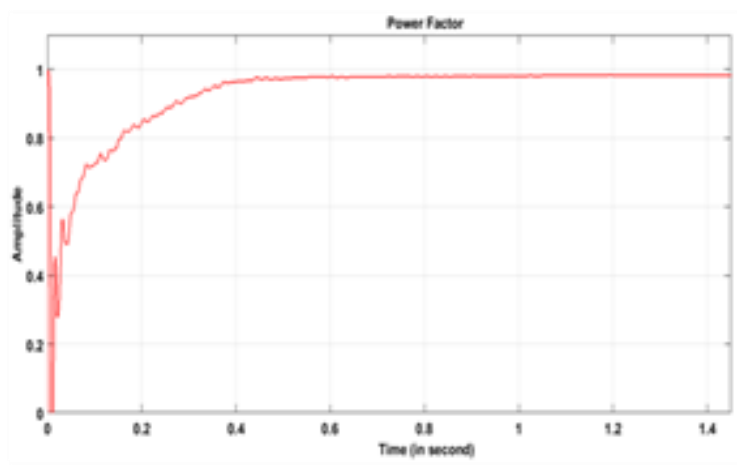

(a)

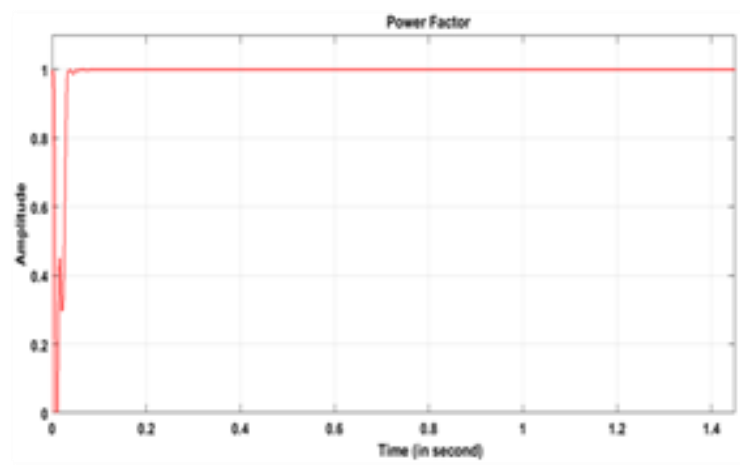

(b)

Figure 13. PF of Bus-3 during capacitive load period with STATCOM based on; (a) PI, (b) ANN

\subsubsection{THD value during capacitive load period}

The harmonics measurement of VSC output current that injected in the system by the STATCOM founded on PI and ANN controller are equal 5.97\% and 4.63\% respectively as clear in Figure 14 (a) and Figure 14 (b). That means the ANN has supported the SVPWM and L-filter to attenuate the major part of current ripples compared with the results obtained by PI. The overall results comparison for cascaded threelevel VSC STATCOM performance based on PI and ANN controller during period of lagging/leading PF load as shown in Table 1.

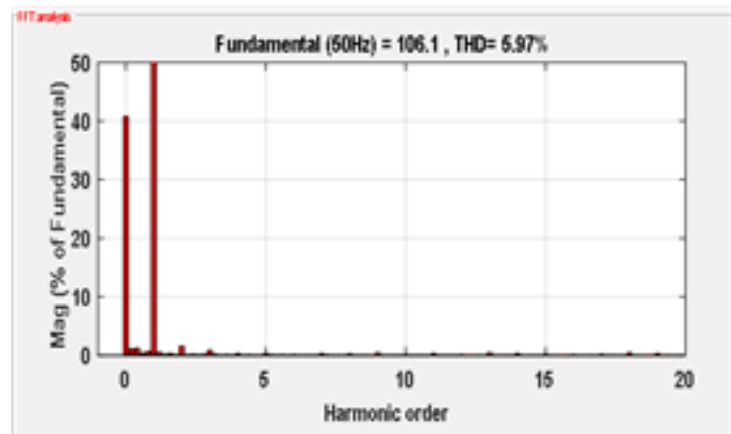

(a)

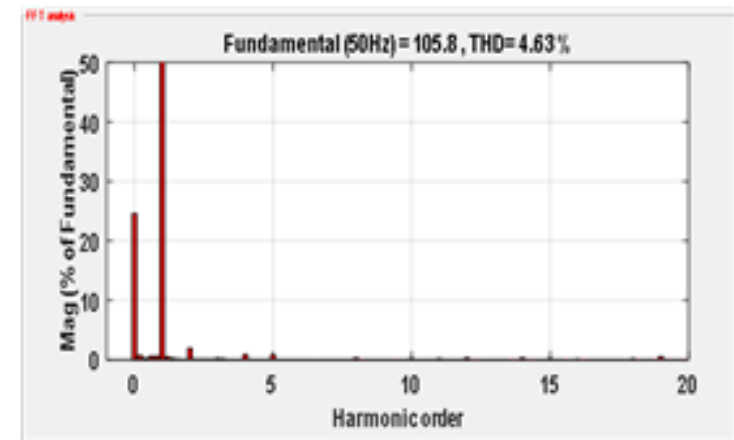

(b)

Figure 14. THD of STATCOM output current during capacitive load period. STATCOM based on; (a) PI, (b) ANN 
Table 1. The overall results comparison for cascaded three-level VSC STATCOM performance based on PI and ANN controller during period of lagging/leading PF load.

\begin{tabular}{lcccc}
\hline \multirow{1}{*}{ Cases } & \multicolumn{4}{c}{ The values during period of } \\
& Lagging PF load (Inductive Load) & \multicolumn{2}{c}{ Leading PF load (Capacitive Load) } \\
& PF & THD & PF & THD \\
\hline Without STATCOM & 0.71 & --- & 0.69 & --- \\
STATCOM With PI & 0.982 & $5.85 \%$ & 0.983 & $5.97 \%$ \\
RT of PI (sec) & 0.451 & --- & 0.843 & --- \\
STATCOM With ANN & 1 & $4.53 \%$ & 1 & $4.63 \%$ \\
RT of ANN (sec) & 0.03 & --- & $29.3 \%$ & --- \\
Improvement of PI & $27.2 \%$ & -- & $31 \%$ & --- \\
Improvement of ANN & $29 \%$ & --- & $4.15 \%$ & -- \\
RT of ANN to PI & $6.65 \%$ & --- & & \\
\hline
\end{tabular}

\section{CONCLUSION}

In this paper, the integration of the ANN controller and a new scheme of SVPWM technique are introduced to enhance the performance of cascaded 3-level VSC STATCOM for improving power factor and eliminating current ripples generated by semiconductor used in VSC. The performance of STATCOM based on ANN control algorithm is successfully proven by results where the PF tends to one and THD of VSC output current tends to value less than 5\% during a period of the lagging/leading PF load as given in Table 1. That means, intelligent control methodology offers fast dynamic response and tracking ability under all operation conditions compared with a traditional controller unit.

\section{REFERENCES}

[1] N. Ismail and W. N. W. Abdullah, "Enhancement of power quality in distribution system using D-STATCOM," in 2010 4th International Power Engineering and Optimization Conference (PEOCO), 2010, pp. 418-423.

[2] [M. M. Almelian, I. I. Mohd, M. A. Omran, and U. U. Sheikh, "Performance of unified power quality conditioner (UPQC) based on fuzzy controller for attenuating of voltage and current harmonics," in IOP Conference Series: Materials Science and Engineering, 2018, p. 012084.

[3] D. M. Soomro and M. Almelian, "Optimal design of a single tuned passive filter to mitigate harmonics in power frequency," ARPN Journal of Engineering and Applied Sciences, vol. 10, pp. 9009-9014, 2015.

[4] B. Singh, R. Saha, A. Chandra, and K. Al-Haddad, "Static synchronous compensators (STATCOM): a review," IET Power Electronics, vol. 2, pp. 297-324, 2009.

[5] M. Mahdianpoor, A. Kiyoumarsi, M. Ataei, R. A. Hooshmand, and H. Karimi, "A multifunctional DSTATCOM for power quality improvement," Turkish Journal of Electrical Engineering \& Computer Sciences, vol. 25, pp. 172-183, 2017.

[6] R. Çötelí, H. Açikgöz, B. Dandil, and S. Tuncer, "Real-time implementation of three-level inverter-based D-STATCOM using neuro-fuzzy controller," Turkish Journal of Electrical Engineering \& Computer Sciences, vol. 26, pp. 2088-2103, 2018.

[7] Y. Xiao-ping, Z. Yan-ru, and W. Yan, "A novel control method for DSTATCOM using artificial neural network," in 2006 CES/IEEE 5th International Power Electronics and Motion Control Conference, pp. 1-4, 2006.

[8] M. T. Ahmad, N. Kumar, and B. Singh, "Generalised neural network-based control algorithm for DSTATCOM in distribution systems," IET Power Electronics, vol. 10, pp. 1529-1538, 2017.

[9] [A. D. Kadu, P. Debre, R. Juneja, and N. Pande, "Application of STATCOM for harmonic mitigation and power factor improvement using direct current control technique," in 2017 Second International Conference on Electrical, Computer and Communication Technologies (ICECCT), pp. 1-4, 2017.

[10] N. P. Wandhare and V. P. Joshi, "Power quality improvement using multi-level inverter as STATCOM," in 2017 IEEE International Conference on Electrical, Instrumentation and Communication Engineering (ICEICE), pp. 1-4, 2017.

[11] P. Sarvghadi, R. Ghazi, and H. Heydari-doostabad, "A new approach for predictive control system design to improve power factor and reduce harmonic current injection using D-STATCOM," in 2017 8th Power Electronics, Drive Systems \& Technologies Conference (PEDSTC), pp. 401-406, 2017.

[12] M. M. Hashempour and T.-L. Lee, "Integrated power factor correction and voltage fluctuation mitigation of microgrid using STATCOM," in 2017 IEEE 3rd International Future Energy Electronics Conference and ECCE Asia (IFEEC 2017-ECCE Asia), pp. 1215-1219, 2017.

[13] J. Jayachandran and R. M. Sachithanandam, "Neural network-based control algorithm for DSTATCOM under nonideal source voltage and varying load conditions," Canadian Journal of Electrical and Computer Engineering, vol. 38, pp. 307-317, 2015.

[14] S. U. Shinde, M. Sharmila, R. S. Patil, and D. V. Malkhede, "Performance comparison of PI \& ANN based STATCOM for $132 \mathrm{KV}$ transmission line," in 2016 International Conference on Electrical, Electronics, and Optimization Techniques (ICEEOT), pp. 2730-2734, 2016.

[15] T. A. Kumar and L. S. Rao, "Improvement of power quality of distribution system using ANN-LMBNN based D-STATCOM," in 2017 Innovations in Power and Advanced Computing Technologies (i-PACT), pp. 1-6, 2017. 
[16] S. Muyeen, H. M. Hasanien, R. Takahashi, T. Murata, and J. Tamura, "Integration of space vector pulse width modulation controlled STATCOM with wind farm connected to multimachine power system," Journal of Renewable and Sustainable Energy, vol. 1, p. 013103, 2009.

[17] S. Tuncer and B. Dandil, "Adaptive neuro-fuzzy current control for multilevel inverter fed induction motor," COMPEL-The international journal for computation and mathematics in electrical and electronic engineering, vol. 27, pp. 668-681, 2008.

[18] A. Cetin, "Design and implementation of a voltage source converter based STATCOM for reactive power compensation and harmonic filtering," METU Electrical and Electronic Engineering Department Phd Thesis, Pages, vol. 222, 2007

[19] M. Gaballah, M. El-Bardini, S. Sharaf, and M. Mabrouk, "Implementation of space vector-PWM for driving two level voltage source inverters," Journal of Engineering Sciences, Assiut University, vol. 39, pp. 871-884, 2011.

[20] U. Shahid, A. Shafique, I. Khan, R. Kashif, and S. Abdul, "Implementation of Multilevel Inverter Using Space Vector Pulse Width Modulation," Science International, vol. 28, 2016.

[21] M. A. A. Ibrahim Alhamrouni, Bazilah Ismail, Mohamed Salem, Awang Jusoh, T. Sutikno "Load Flow Based Voltage Stability Indices for Voltage Stability and Contingency Analysis for Optimal Location of STATCOM in Distribution Network with Integrated Distributed Generation Unit," TELKOMNIKA, vol. 16, p. 14, 2018.

[22] L. M. Tolbert and F. Z. Peng, "Multilevel converters for large electric drives," in APEC'98 Thirteenth Annual Applied Power Electronics Conference and Exposition, pp. 530-536, 1998.

[23] A. Majed and Z. Salam, "Multilevel D-STATCOM for sag and swell mitigation using modulation index control," in 2015 IEEE Conference on Energy Conversion (CENCON), pp. 187-192, 2015.

[24] C. K. Sundarabalan, and K. Selvi, "Power quality enhancement in power distribution system using artificial intelligence based dynamic voltage restorer," International Journal on Electrical Engineering and Informatics, vol. 5, p. 433, 2013. 